\title{
Is Anxiety a Rising Concern during COVID-19 Pandemic among Healthcare Workers?
}

\author{
Pooja R Murthy ${ }^{1}$, KV Venkatesha Gupta², AK Ajith Kumar ${ }^{3}$ \\ Keywords: Anxiety, COVID 19, Healthcare workers. \\ Indian Journal of Critical Care Medicine (2020): 10.5005/jp-journals-10071-23434
}

To the Editor,

The corona virus disease 19 (COVID 19) spread was declared as a pandemic by the World Health Organization in March 2020. ${ }^{1}$ Anxiety is a rising concern in the current COVID pandemic. Healthcare workers (HCWs) are particularly vulnerable with fears about infecting their loved ones, inadequate personal protective equipment (PPE), long working hours, and lack of adequate healthcare when infected. ${ }^{2}$ This study was designed to understand anxiety in HCWs.

We interviewed $296 \mathrm{HCWs}$ above 18 years of age using an online Web-based version of Hamilton anxiety scale. The anxiety was of four grades, zero grade, mild grade $(<17)$, moderate grade (18 to $24)$, and severe grade ( 25 to 30 ).

Data were analyzed by using SPSS version 22.0. The study consisted of $184(62.2 \%)$ males and 112 (37.8\%) females. The distribution of HCWs included physicians handling COVID areas (48\%), physician specialists working in non-COVID areas (26\%), nurses working in COVID areas (10.5\%), nurses and other HCWs in non-COVID areas (10.1\%), and hospital administrators (5.4\%). Among the 296 participants, 27 (9.1\%) participants had no anxiety, 241 (81.4\%) participants had mild anxiety, 11 (3.7\%) participants had moderate anxiety, and 17 (5.7\%) participants had severe anxiety (Fig. 1). Statistical analysis showed that $53 \%$ of males had mild anxiety compared to $28.4 \%$ females. However, female participants (6.7\%) had higher levels of moderate to severe anxiety when compared to male participants (2.7\%), which was statistically significant ( $p$ value $<0.001$ ). Mild anxiety was reported in $16.9 \%$ of

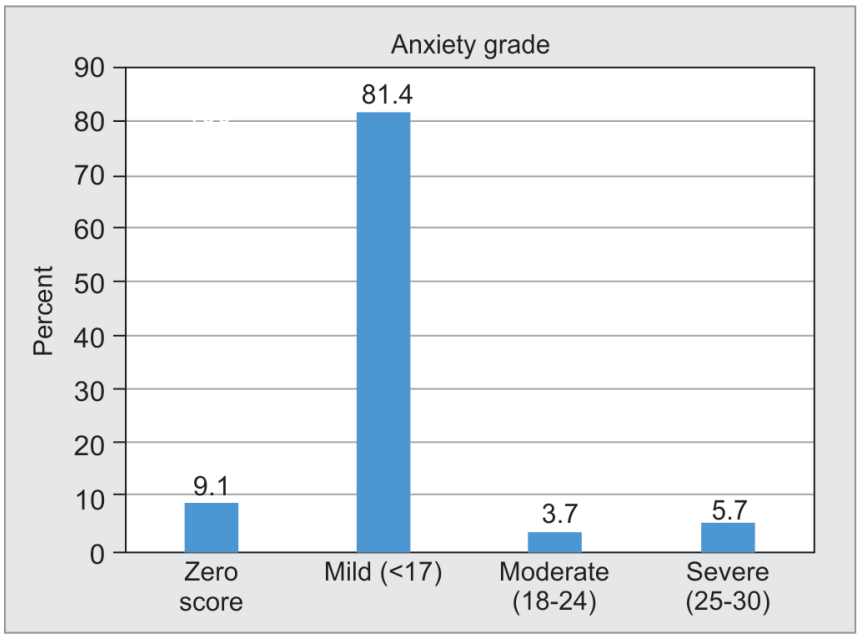

Fig. 1: Distribution of anxiety grades among healthcare workers

\footnotetext{
${ }^{1-3}$ Department of Critical Care Medicine, Manipal Hospital, Bengaluru, Karnataka, India
}

Corresponding Author: Pooja R Murthy, Department of Critical Care Medicine, Manipal Hospital, Bengaluru, Karnataka, India, Phone: +919769070976, e-mail: poojamurthy2016@gmail.com

How to cite this article: Murthy PR, Venkatesha Gupta KV, Ajith Kumar AK. Is Anxiety a Rising Concern during COVID-19 Pandemic among Healthcare Workers? Indian J Crit Care Med 2020;24(5):369-370.

Source of support: Nil

Conflict of interest: None

participants in the age-group between 20 and 30 years, 35.5\% in the age-group of 30 to 40 years, $18.9 \%$ in the age-group between 40 years and 50 years, and $10.1 \%$ of older participants (more than 50 years). No statistically significant difference in anxiety was observed between any of the age-groups ( $p$ value 0.113 ). The level of moderate to severe anxiety was higher among nurses and physicians working in COVID areas compared to the specialists working in non-COVID areas and hospital administrators. No difference in anxiety levels was observed in HCWs between public and private hospitals (Fig. 2).

After the COVID outbreak in China, the focus is mainly to break the chain of transmission, concentrate on various therapeutic strategies, vaccine research, and arrange logistics for proper handling of patients. The focus on mental health is also gaining importance.

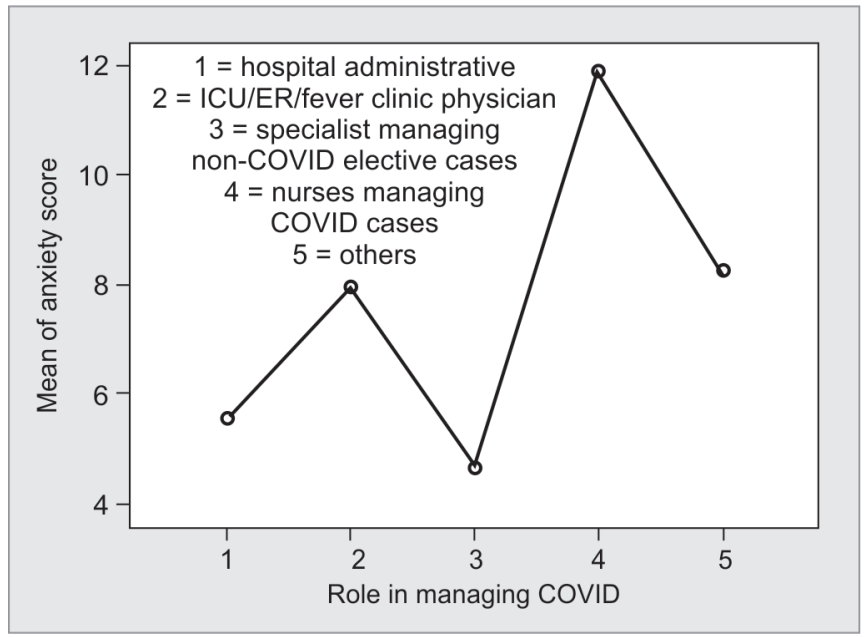

Fig. 2: Distribution of anxiety in different groups of participants

(0) The Author(s). 2020 Open Access This article is distributed under the terms of the Creative Commons Attribution 4.0 International License (https://creativecommons. org/licenses/by-nc/4.0/), which permits unrestricted use, distribution, and non-commercial reproduction in any medium, provided you give appropriate credit to the original author(s) and the source, provide a link to the Creative Commons license, and indicate if changes were made. The Creative Commons Public Domain Dedication waiver (http://creativecommons.org/publicdomain/zero/1.0/) applies to the data made available in this article, unless otherwise stated. 
Our assessment demonstrated that most of the participants (90.9\%) had anxiety and around $10 \%$ had moderate to severe anxiety. The levels of moderate to severe anxiety were higher in females compared to males. It was also noted that HCWs involved in the care of the COVID patients had significantly higher anxiety than those who were not.

Other studies have also shown a similar picture. In a survey done among HCWs in hospitals treating COVID patients in Wuhan, China, an increase in psychological burden was seen among female participants and nurses who were directly involved in treating and caring COVID patients. ${ }^{3}$

Another study conducted in 662 participants (50\% of which were HCWs) in India showed significant feelings of anxiety, apprehension, and worries due to COVID 19 pandemic. ${ }^{4}$ An article published in April 2020 in JAMA regarding understanding and addressing the sources of anxiety among HCWs, it guides us to use strategies such as addressing PPE shortage, reducing the working hours, and providing adequate support to females for childcare as few examples to mitigate anxiety. ${ }^{2}$
Thus, anxiety is a hidden problem in HCWs. We feel that preventive strategies such as screening for anxiety, education about transmission of COVID 19, and psychosocial support are the need of the hour. As the whole world is gearing to handle the pandemic, issues regarding the anxiety of frontline warriors also need to be addressed.

\section{References}

1. Cucinotta D, Vanelli M. WHO declares COVID-19 a pandemic. Acta Biomed 2020;91(1):157-160. DOI: 10.23750/abm.v91i1.9397.

2. Shanafelt T, Ripp J, Trockel M. Understanding and addressing sources of anxiety among health care professionals during the COVID-19 pandemic. JAMA 2020. DOI: 10.1001/jama.2020.5893.

3. Lai J, Ma S, Wang Y, Cai Z, Hu J, Wei N, Wu J, et al. Factors associated with mental health outcomes among health careworkers exposed to coronavirus disease 2019. JAMA Netw Open 2020;3(3):e203976. DOI: 10.1001/jamanetworkopen.2020.3976.

4. Roy D, Tripathy S, Kar SK, Sharma N, Verma SK, Kaushal V. Study of knowledge, attitude, anxiety \& perceived mental healthcare need in Indian population during COVID-19 pandemic. Asian J Psychiatr 2020;51:102083. DOI: 10.1016/j.ajp.2020.102083. 